\title{
Perceived occurrence of an adverse event affects patient-reported outcomes after total hip replacement
}

\author{
Charlotte V. E. Carpenter ${ }^{1 *}$ (D), Vikki Wylde ${ }^{1,2}$, Andrew J. Moore ${ }^{1}$, Adrian Sayers ${ }^{1}$, Ashley W. Blom ${ }^{1,2}$ and
} Michael R. Whitehouse ${ }^{1,2}$

\begin{abstract}
Background: Dislocation, periprosthetic fracture and infection are serious complications of total hip replacement (THR) and which negatively impact on patients' outcomes including satisfaction, quality of life, mental health and function. The accuracy with which patients report adverse events (AEs) after surgery varies. The impact of patient self-reporting of AEs on patient-reported outcome measures (PROMs) after THR is yet to be investigated. Our aim was to determine the effect of confirmed and perceived AEs on PROMs after primary THR.
\end{abstract}

Methods: A prospective single-centre cohort study of patients undergoing primary THR, with one-year follow-up, was performed. Participants completed forms pre-operatively and 3, 6, 9 and 12 months post-operatively, including Work Productivity and Activity Impairment (WPAI), Western Ontario and McMaster Universities Osteoarthritis Index (WOMAC), EuroQol-5D-3 L (EQ5D), Self-Administered Patient Satisfaction (SAPS) and AE reporting questionnaires. Results were reported in three groups: No AE, reported but not confirmed AE and confirmed AE. A generalised linear model was used to compare among groups using robust standard errors (SE).

Results: Forty-one AEs were reported in a cohort of 417 patients (234 females), with 30 AEs reported by 3 months. Eleven (27 reported) infections, two (six reported) periprosthetic fractures and two (eight reported) dislocations were confirmed. Those in the no AE group reported significantly better outcomes that the reported AE group as measured by WOMAC Co-Eff $14.27(p=0.01)$, EQ5D - $0.128(p=0.02)$ and SAPS $-9.926(p=0.036)$ and the combined reported and confirmed AE groups as measured by WOMAC Co-Eff $13.72(p=0.002)$, EQ5D $-0.129(p=$ $0.036)$ and SAPS $-11.512(p=0.004)$. No significant differences were seen in WPAI among groups.

Conclusions: Patients who report AEs have worse outcomes than those who do not, regardless of whether the AEs can be confirmed by standard medical record review methods. The observed negative trends suggest that patient perception of AEs may influence patient outcome in a similar way to those with confirmed AEs.

Keywords: Total hip replacement, Outcomes, Adverse events, Patient reporting

\section{Introduction}

In England and Wales approximately 97,000 primary total hip replacements (THR) were performed during 2017 [1]. Demand for THR is likely to increase with an ageing population [2,3]. THR is a successful option for the treatment of chronic hip pain with $90 \%$ of patients

\footnotetext{
* Correspondence: flossie.carpenter@bristol.ac.uk

${ }^{1}$ Musculoskeletal Research Unit, Translational Health Sciences, Bristol Medical School, 1st Floor Learning \& Research Building, Southmead Hospital, Bristol BS10 5NB, UK

Full list of author information is available at the end of the article
}

satisfied with their outcome [4]. Dislocation, periprosthetic fracture and infection are relatively rare but serious complications of THR. They often require hospital admission, further major operations and ongoing hospital-based care posing a significant burden both to the patient and health care system [5-7].

Adverse events (AEs) significantly impact on patients' outcomes after THR. Dislocation, particularly recurrent dislocations, can negatively impact on patient satisfaction, quality of life, mental health and function, including self-care and daily activities [8]. After post-operative

(c) The Author(s). 2020 Open Access This article is distributed under the terms of the Creative Commons Attribution 4.0 International License (http://creativecommons.org/licenses/by/4.0/), which permits unrestricted use, distribution, and reproduction in any medium, provided you give appropriate credit to the original author(s) and the source, provide a link to the Creative Commons license, and indicate if changes were made. The Creative Commons Public Domain Dedication waiver (http://creativecommons.org/publicdomain/zero/1.0/) applies to the data made available in this article, unless otherwise stated. 
periprosthetic fracture, approximately $50 \%$ of patients do not return to previous levels of mobility and half require assistance with daily living [9]. Prosthetic joint infection often requires major revision surgery and patients experience deeply negative changes in their quality of life enduring severe pain, long periods of immobility, an inability to participate in daily work and leisure activities, social isolation and psychological suffering $[10,11]$. In one study, patients with prosthetic joint infection reported poorer outcomes on the Western Ontario and McMaster Universities Osteoarthritis Index (WOMAC), Assessment of Quality of Life (AQoL) and the 36-Item Short Form (SF-36), and 12\% of patients rating their current situation equivalent to, or worse than, death [12].

AEs reported by patients may provide information about subjective experiences following a surgical procedure but often reveal different results from AEs recorded in medical records. The accuracy with which patients report AEs after surgical procedures varies widely in the literature. Concordance between patient reports and medical records is between 0 and $58 \%$ at 30 days after all surgical procedures [13] and $36-95 \%$ at 3 years after hip and knee replacement [14]. Agreement between patient reports and insurance claims after orthopaedic procedures showed poor to moderate agreement (kappa 0 to 0.53) for complications, [15] rising to 69\% agreement when patients are telephoned to confirm AEs reported via mail surveys [16].

Previous studies have evaluated the accuracy with which patients report AEs after joint replacement surgery and the impact of the most common AEs on patient-reported outcome measures (PROMs) [13-16]. However, the impact of self-reporting of an $\mathrm{AE}$ on PROMs after THR is yet to be investigated.

The aim of this study was to evaluate the effect of perceived and confirmed adverse events on patient-reported outcome measures over the first 12 months after primary THR.

\section{Patients and methods}

A prospective single-centre cohort study was conducted examining the impact of patient reporting of AEs on PROMs following primary THR. Consecutive patients undergoing a primary THR between January 2012 and January 2013 were screened for eligibility prior to attending a preoperative assessment outpatient appointment. Patients meeting the inclusion criteria were invited to participate at this appointment. Patients were eligible for inclusion if they were due to undergo primary elective THR, were able to provide consent to participate and were able to understand and complete the English language questionnaires. Exclusion criteria were patients undergoing revision arthroplasty, patients who were unwilling or unable to provide consent and patients who were unable to understand or complete the questionnaires [Fig. 1]. Participation was voluntary, and patients provided verbal consent to participate. This study was part of a larger service evaluation project of THR and total knee replacement in this centre and ethical approval was not required according to the National Research Ethics Service guidelines. Participants were asked to complete questionnaires at five timepoints: pre-operatively and at $3,6,9$ and 12 months postoperatively. Clinical follow-up and post-operative rehabilitation were determined by the treating surgeon and not affected by inclusion in this study. The preoperative questionnaire assessed work status using the Work Productivity and Activity Impairment (WPAI), [17] hip function using the WOMAC [18] and healthrelated quality of life using the EuroQol-5D-3 L (EQ5D) [19]. The post-operative questionnaire included all the pre-operative questionnaires as well as the SelfAdministered Patient Satisfaction scale (SAPS) [20] and an $\mathrm{AE}$ reporting questionnaire. The pre-operative questionnaire was administered and completed at a preoperative assessment outpatient appointment, no more than 60 days prior to the date of the primary THR. Postoperative questionnaires were posted to participants,

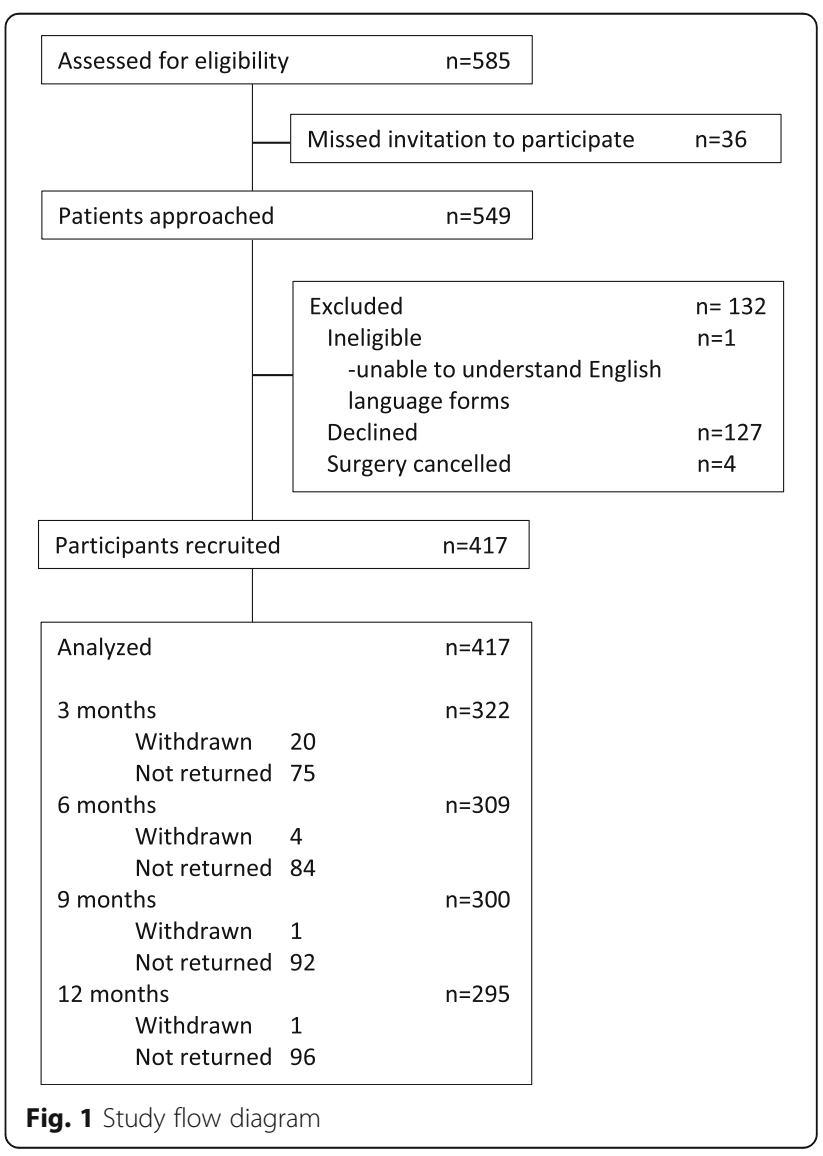


and if no response was received in 2 weeks, a reminder was sent.

The WPAI is an instrument to measure impairment in both paid and unpaid work. It can be adapted to measure absence and impairment due to a specific health problem [17]. A score displayed as a percentage may be calculated for work time missed, impairment while working, overall work impairment and activity impairment due to the health problem. The WPAI was completed by participants in employment. The percentage activity impairment represents the degree to which the hip due to be or that had been replaced affected regular activities.

WOMAC is a 24-item questionnaire designed to measure pain, function and stiffness in patients with osteoarthritis of the hip or knee [18]. It uses a 5-point Likert scale from 0 to 4 for each question (giving a total scale of 0-96) with higher scores indicating worse outcomes. A percentage score for each subscale of the WOMAC and a total was calculated, giving a score out of 100 for stiffness, pain, function and total WOMAC score.

EQ5D is a standardised, non-disease specific questionnaire for evaluating health-related quality of life in five dimensions, including mobility, self-care, usual activities, pain or discomfort and anxiety or depression [19]. The EQ5D index is derived from a standardised value set to provide a single value for health status, where one represents full health.

SAPS is a short questionnaire used to evaluate patient satisfaction with total hip and knee replacement [20]. Four items are scored on a 4-point Likert scale with responses from very dissatisfied to very satisfied. The scale score is the unweighted mean of the scores with 100 being most satisfied and 25 the least.

Study-specific questionnaires were used to evaluate AEs. Participants were asked if they had any problem with infection in the joint or wound, a dislocation of the THR or a fracture around the THR, after their surgery. Participants were asked to record details of these events and were asked if any other complications had occurred [Appendix 1]. The first report of an $\mathrm{AE}$ episode was counted, in the case of infection, if there was an infection that persisted and hence reported at multiple time points, it was only counted once.

For AEs reported by participants hospital systems and primary care records were interrogated to see if the $\mathrm{AE}$ could be confirmed. Hospital medical records were searched for hospital admissions and discharge documentation, outpatient clinic letters, operation records, radiology and microbiology reports. Local picture archiving and communications imaging systems were searched for evidence of dislocation or periprosthetic fracture. Primary care records were searched for documentation of an $\mathrm{AE}$, post-operative general practice attendance or antibiotic prescribing at the time of the recorded AE.

Missing data were handled according to the user guide for each PROM. Data were analysed using STATA (version 13, StataCorp, College Station, TX, USA). Results are reported in three groups of participants:

1) No AE group: participants who reported no AE.

2) Reported group: participants who reported an $\mathrm{AE}$ which was not confirmed after searching medical records as described above.

3) Confirmed AE group: participants who reported an $\mathrm{AE}$ that was confirmed after medical record search.

Data were checked for normal distribution using a Shapiro-Wilks test and histogram plots. Where data were not normally distributed, central tendency is described as median value with inter-quartile range (IQR). PROMs data were compared among groups at 12 months using a generalised linear model(GLR) with robust standard errors (SE) in order to account for the non-normal distribution of data. The models were adjusted to account for age, gender and body mass index (BMI). The first model describes the relationship of the no $\mathrm{AE}$ group to the reported group and the confirmed group. The second model was constrained to assume no difference between the reported and confirmed groups and the Akaike information criteria (AIC) between the models were then compared using a likelihood ratio test (LRtest). A $p$-value of $<0.05$ was considered statistically significant.

\section{Results}

Pre-operatively 549 patients were invited to participate and 417 were recruited. At first follow-up 322 responses were received. By 12 months, there were a further 27 non-responders and six participants withdrew from the study.

Baseline demographics and PROMs scores are displayed in Table 1 and were similar among the groups.

Forty-one AEs were reported by 35 participants with three participants reporting two AEs and one participant reporting four (Table 2).

Most $(n=30)$ AEs were reported by 3 months postoperation. Fifteen AEs were confirmed by a review of medical records and 26 could not be confirmed. Eleven AEs were identified on review of secondary care records and a further four, all superficial wound infections treated by the GP, were identified after review of primary care records. Infection was the most commonly reported $\mathrm{AE}$, with the majority (24 of 27 ) reported at 3 months. Eleven infections were confirmed, 10 were superficial wound infections and one a prosthetic joint infection.

Pre-operatively, PROMs were similar across each of the three groups, except for the EQ5D which was lower 
Table 1 Patient demographics and baseline data. (IQR: interquartile range, BMI: body mass index, WPAI: Work Productivity and Activity Impairment, EQ5D: EuroQol-5D-3 L, WOMAC: Western Ontario and McMaster Universities Osteoarthritis Index, SAPS: SelfAdministered Patient Satisfaction scale)

\begin{tabular}{lllll}
\hline Variable & $\begin{array}{l}\text { No Adverse Event } \\
(n=382)\end{array}$ & $\begin{array}{l}\text { Reported } \\
(n=20)\end{array}$ & $\begin{array}{l}\text { Confirmed } \\
(n=15)\end{array}$ & $\begin{array}{l}\text { All participants } \\
(n=417)\end{array}$ \\
\hline Age (IQR) & $68(57,75)$ & $61(57,75)$ & $67(50,75)$ & $67(57,75)$ \\
Female sex (\%) & $213(56 \%)$ & $12(60 \%)$ & $8(53 \%)$ & $234(56 \%)$ \\
BMI (IQR) & $28(25,31)$ & $33(29,36)$ & $30(26,35)$ & $28(25,32)$ \\
Retired (\%) & $222(60 \%)$ & $17(55 \%)$ & $7(50 \%)$ & $240(59 \%)$ \\
WPAI (IQR) & $70(50,80)$ & $70(70,90)$ & $65(40,80)$ & $70(50,80)$ \\
EQ5D (IQR) & $0.52(0.06,0.70)$ & $0.52(0.6,0.62)$ & $0.16(0.02,0.69)$ & $0.52(0.6,0.69)$ \\
WOMAC (IQR) & $59.9(50,69.8)$ & $60.1(54.2,77.1)$ & $59.4(55.2,70.8)$ & $59(50,70)$ \\
\hline
\end{tabular}

in the confirmed AE group. All outcomes in all groups improved with time (Table 3).

All PROMs showed the greatest improvement in the first 3 months post-operatively. At each post-operative time point, the confirmed $\mathrm{AE}$ and reported $\mathrm{AE}$ group showed less improvement than the no $\mathrm{AE}$ group for WOMAC, EQ5D and SAPS (Fig. 2). By 6 months the no $\mathrm{AE}$ and reported $\mathrm{AE}$ groups had no activity impairment associated with their THR.

PROMs at the end-point of 12 months were compared among groups (Table 4).

Both the WOMAC and EQ5D demonstrated a significantly better score for the no AE group when compared to the reported groups. Both WOMAC and EQ5D demonstrated a significantly improved between the no $\mathrm{AE}$ group and the reported and confirmed groups in the constrained model and the AIC and LRtest indicate equivalence between the reported and confirmed groups. The no AE group showed significantly better satisfaction than the reported and confirmed groups and the comparison of models suggests there may be a difference among all three results. WPAI demonstrated no significant differences among groups.

\section{Discussion}

In this study, $41 \mathrm{AEs}$ were reported by 35 patients from a cohort of 417 patients undergoing primary THR.
Fifteen of the reported AEs were confirmed by primary and secondary care medical records. Most AEs were reported by 3 months post-operatively. Eleven infections, two periprosthetic fractures and two dislocations were confirmed. Participants in the reported AE group and confirmed AE group had similar PROMs at each timepoint, worse than those who did not report an AE.

Three quarters of reported and two thirds of confirmed AEs were reported by 3 months. Most studies have differing follow-up end points, and early reporting of AEs varies. Blom et al. reported $64 \%$ of dislocations occur within the first 3 months with $8-11$ year follow-up [6] and Phillips et al. reported $90 \%$ of dislocations and $85 \%$ of infections had occurred within 3 months, with follow-up of 6 months [21]. Infection represented 11 of 12 confirmed AEs at 3 months, 10 of which were superficial wound infections. Surgical site infection after total hip and knee replacement is diagnosed at a median 17 (11-23) days post-operatively [22] and Lamagni reported that $85 \%$ of infections occur within the first 30 days of surgery [23]. In this study, none of the confirmed superficial wound infections were subsequently revised for deep prosthetic infection. Reporting of periprosthetic fractures follows a different pattern, with half of all fractures occurring intra-operatively, $24 \%$ of which are identified post-operatively [24]. In our study, fractures identified at the time of operation were excluded,

Table 2 Adverse events by group, reported but not confirmed or confirmed adverse event and timepoint reported. Note: the number of AE (41) is greater than the number of participants that reported AE (35) as some reported more than one event

\begin{tabular}{|c|c|c|c|c|c|c|c|c|}
\hline \multirow[b]{2}{*}{ ADVERSE EVENTS } & \multicolumn{2}{|c|}{ INFECTION } & \multicolumn{2}{|c|}{ PERIPROSTHETIC FRACTURE } & \multicolumn{2}{|c|}{ DISLOCATION } & \multicolumn{2}{|l|}{ TOTAL } \\
\hline & Reported & Confirmed & Reported & Confirmed & Reported & Confirmed & Reported & Confirmed \\
\hline 3 MONTHS & 13 & 11 & 2 & 1 & 3 & 0 & 18 & 12 \\
\hline 6 MONTHS & 1 & 0 & 1 & 0 & 1 & 1 & 3 & 1 \\
\hline 9 MONTHS & 2 & 0 & 0 & 1 & 0 & 1 & 2 & 2 \\
\hline 12 MONTHS & 0 & 0 & 1 & 0 & 2 & 0 & 3 & 0 \\
\hline TOTAL & 16 & 11 & 4 & 2 & 6 & 2 & 26 & 15 \\
\hline
\end{tabular}


Table 3 A comparison of patient reported outcomes over time by group. (AE: adverse event, IQR: interquartile range, WPAl: Work Productivity and Activity Impairment, EQ5D: EuroQol-5D-3 L, WOMAC: Western Ontario and McMaster Universities Osteoarthritis Index, SAPS: Self-Administered Patient Satisfaction scale)

\begin{tabular}{|c|c|c|c|c|c|c|c|c|c|c|}
\hline & $\begin{array}{l}\text { Pre-op } \\
\text { Median (IQR) }\end{array}$ & $n$ & $\begin{array}{l}3 \text { Months } \\
\text { Median (IQR) }\end{array}$ & $n$ & $\begin{array}{l}6 \text { Months } \\
\text { Median (IQR) }\end{array}$ & $n$ & $\begin{array}{l}9 \text { Months } \\
\text { Median (IQR) }\end{array}$ & $n$ & $\begin{array}{l}12 \text { Months } \\
\text { Median (IQR) }\end{array}$ & $n$ \\
\hline \multicolumn{11}{|l|}{ WPAI } \\
\hline No AE & $70(50,80)$ & 106 & $20(10,30)$ & 76 & $10(0,20)$ & 71 & $0(0,20)$ & 68 & $0(0,20)$ & 72 \\
\hline Reported & $70(70,90)$ & 6 & $25(10,30)$ & 6 & $0(0,10)$ & 3 & $0(0,50)$ & 3 & $0(0,20)$ & 3 \\
\hline Confirmed & $65(40,80)$ & 4 & $30(20,40)$ & 4 & $20(0,20)$ & 3 & $205,30)$ & 4 & $15(5,25)$ & 4 \\
\hline \multicolumn{11}{|l|}{ EQ5D } \\
\hline No AE & $0.52(0.6,0.69)$ & 395 & $0.76(0.62,1)$ & 313 & $0.8(0.69,1)$ & 298 & $0.81(0.69$ & 285 & $0.88(0.71,1)$ & 289 \\
\hline Reported & $0.52(0.16,0.59)$ & 18 & $0.62(0.52,0.76)$ & 17 & $0.7(0.55,0.91)$ & 16 & $0.7(0.62,0.78)$ & 14 & $0.7(0.52,0.82)$ & 14 \\
\hline Confirmed & $0.16(0.02,0.69)$ & 15 & $0.59(0.36,0.76)$ & 15 & $0.75(0.64,1)$ & 12 & $0.7(0.22,0.91)$ & 12 & $0.76(0.71,1)$ & 13 \\
\hline \multicolumn{11}{|l|}{ WOMAC } \\
\hline No AE & $59.9(50,69.8)$ & 364 & $16.7(8.3,31.2)$ & 269 & $12.5(4.4,27.1)$ & 267 & $10.4(3.1,23)$ & 256 & $7.3(2.1,16.8)$ & 256 \\
\hline Reported & $60.1(54.2,77.1)$ & 18 & $29.2(15.2,40.1)$ & 16 & $22.9(8.3,50)$ & 17 & $26(12.5,40.1)$ & 16 & $22.4(7.3,46.9)$ & 14 \\
\hline Confirmed & $59.4(55.2,70.8)$ & 15 & $25.9(15.6,51)$ & 15 & $21.75 .2,33.3)$ & 11 & $26.5(6.5,29.9)$ & 12 & $15.6(5.2,29.1)$ & 13 \\
\hline \multicolumn{11}{|l|}{ SAPS } \\
\hline No AE & & & $93.8(81.3,100)$ & 268 & $100(81.3,100)$ & 250 & $100(81.3,100)$ & 247 & $100(87.5,100)$ & 248 \\
\hline Reported & & & $78.1(75,100)$ & 18 & $87.5(68.8,100)$ & 17 & $93.8(75,100)$ & 15 & $87.5(75,100)$ & 14 \\
\hline Confirmed & & & $81.3(68.8,100)$ & 13 & $81.3(71.9,100)$ & 12 & $87.5(62.5,100)$ & 12 & $81.3(62.5,100)$ & 11 \\
\hline
\end{tabular}

however both confirmed fractures occurred at the time of surgery but were not reported until subsequent follow-up. Post-operative periprosthetic fracture occurs in $1.7 \%$ of primary THR with a linear survival curve over 10 years, suggesting that the rate of fracture does not change over time [25]. The timing of the AEs reported in our study are in keeping with the published literature.

Fifteen of a reported 41 AEs were confirmed in our study. There are differences between self-reported AE rates and those confirmed by medical records, but rates vary in the literature. One study confirming patientreported post-operative complications using medical records found agreement in $0-41 \%$ of cases [13]. Surgical site infection had agreement (kappa) of 0.53 (95\%CI, 0.17 to 0.89 ) and 0 for fracture/dislocation in a study of internet-based patient reporting across orthopaedic procedures [15]. Agreement tends to be higher when patients are contacted by telephone to confirm complications which may represent confounding as patients are confirming their own self-reports. However, it may be that patients misreport $\mathrm{AE}$ due to lack of comprehension or literacy when asked to complete a questionnaire, rather than by an interviewer. When patients were contacted by telephone by a surgeon, to confirm reported AEs, a concordance of $69 \%$ was achieved [16]. Alazzawi et al. confirmed $95 \%$ of infections, $52 \%$ of dislocations and $57 \%$ of periprosthetic fractures after primary hip and knee replacement using medical record review and surveying general practitioners [14]. Our overall agreement of $37 \%$ is at the lower end of the spectrum reported to date. Most of the reported AEs in our study were not confirmed on review of medical records. Fritz et al. discovered that participants may accurately report a complication that occurred after surgery which may not have been documented in the medical records [13]. Greenbaum identified that $72 \%$ of patients with dislocation and $7 \%$ of fractures present to an outside hospital after THR [16]. Despite rigorous exploration of regional medical records, some AEs may not have been confirmed if patients presented to hospitals outside the region, but these should still have been captured by primary care records as hospitals are required to report admissions to hospital to the primary care physician and this, in turn, is documented in the primary care records. However, most unconfirmed AEs are explained by patients who report an $\mathrm{AE}$ that did not occur. Reasons for these reports include misinterpretation of symptoms as AEs, erroneously reporting an $\mathrm{AE}$ that did not occur or accurately reporting an $\mathrm{AE}$ that occurred prior to surgery $[13,16]$. A large portion of patients reporting an AE, misreport the occurrence of AEs after THR. Regardless of the reason, self-reporting of an $\mathrm{AE}$ appears to be associated with outcome. Studies using medical record review to identify AEs after surgery may, therefore, underestimate the number of patients negatively impacted by their surgical procedure.

In this study, participants who reported an $\mathrm{AE}$ had outcomes similar to those with a confirmed AE. Both 


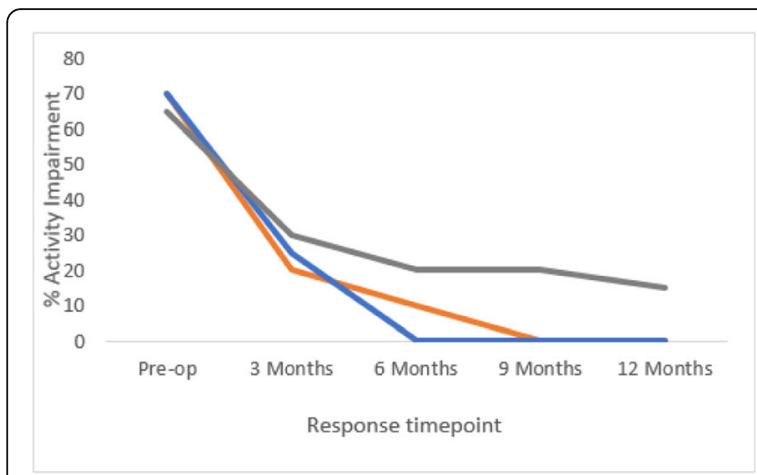

WPAI \% activity impairment by adverse event group and timepoint

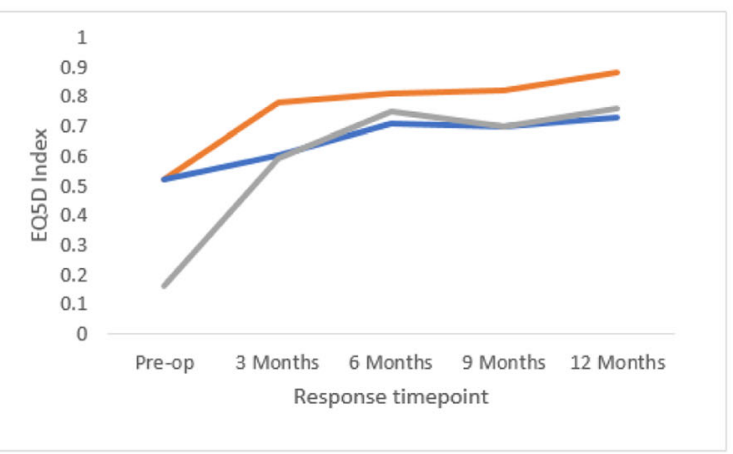

EQ5D index by adverse event group and timepoint

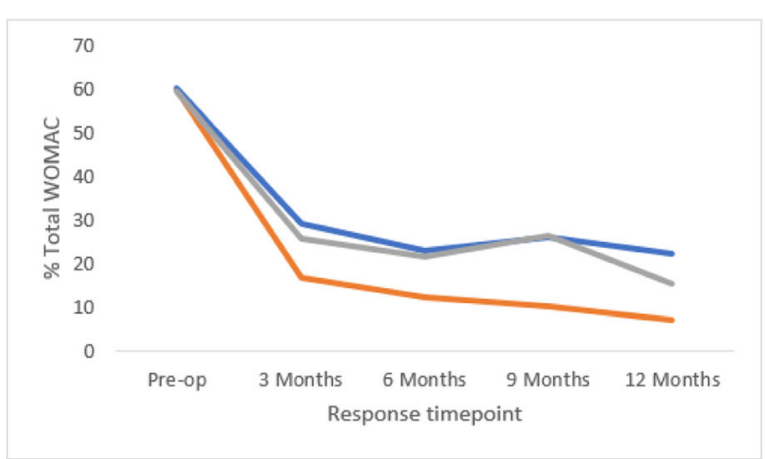

WOMAC score by adverse event group and timepoint

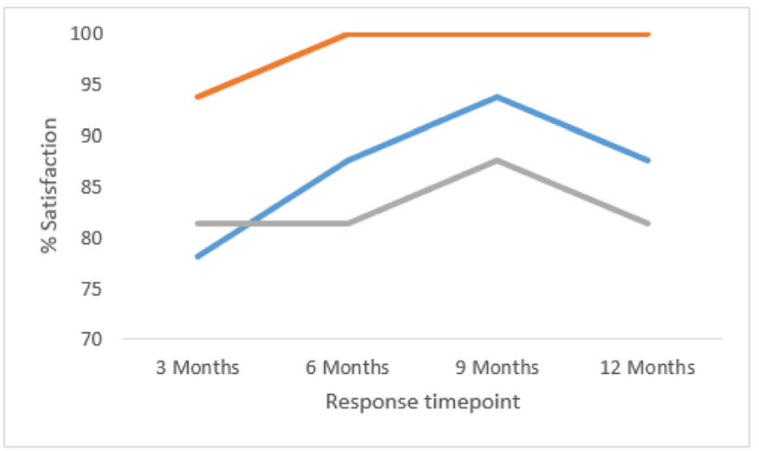

Percentage satisfaction by adverse events group and timepoint

No reported $A E$ - Reported $A E \quad$ Confirmed $A E$

Fig. 2 PROMs by adverse event group and timepoint. (WPAl: Work Productivity and Activity Impairment; WOMAC: Western Ontario and McMaster Universities Osteoarthritis Index; EQ5D:EuroQol-5D-3 L)

Table 4 A comparison of patient reported outcome measures among groups at 12-months; Model 1: GLR describing the relationship of the no AE group to the reported group and the confirmed group. Model 2: GLR describing the relationship of the no AE group to the reported and confirmed group, when constrained to assume no difference between these two groups. Group 1: No AE group, Group 2: Reported group, Group 3: Confirmed group. (WOMAC: Western Ontario and McMaster Universities Osteoarthritis Index, EQ5D: EuroQol-5D-3 L, SAPS: Self-Administered Patient Satisfaction scale, WPAl: Work Productivity and Activity Impairment)

\begin{tabular}{|c|c|c|c|c|c|c|c|}
\hline PROM & Model & Groups & Co-efficient & $95 \% \mathrm{Cl}$ & $p$-value & $\mathrm{AlC}$ & LRtest \\
\hline \multirow[t]{3}{*}{ WOMAC } & Model 1: & 1 to 2 & 14.27 & $(3.2,25.3)$ & $p=0.01$ & 8.5 & \\
\hline & & 1 to 3 & 13.13 & $(-0.68,26.9)$ & $p=0.06$ & & \\
\hline & Model 2: & 1 to (2 and 3 ) & 13.72 & $(4.8,22.6)$ & $p=0.002$ & 8.49 & 0.85 \\
\hline \multirow[t]{3}{*}{ EQ5D } & Model 1: & 1 to 2 & -0.128 & $(-0.25,-0.006)$ & $p=0.04$ & 0.015 & \\
\hline & & 1 to 3 & -0.129 & $(-0.34,0.079)$ & $p=0.22$ & & \\
\hline & Model 2: & 1 to (2 and 3 ) & -0.1285 & $(0.25,-0.008)$ & $p=0.036$ & 0.0081 & 0.9 \\
\hline \multirow[t]{3}{*}{ SAPS } & Model 1: & 1 to 2 & -9.926 & $(-19.2,-0.7)$ & $p=0.036$ & 8.11 & \\
\hline & & 1 to 3 & -13.5 & $(-26.6,-0.5)$ & $p=0.042$ & & \\
\hline & Model 2: & 1 to (2 and 3 ) & -11.515 & $(-19.4,-3.7)$ & $p=0.004$ & 8.1 & 0.5 \\
\hline \multirow[t]{3}{*}{ WPAI } & Model 1: & 1 to 2 & -6.805 & $(-18.7,5.2)$ & $p=0.264$ & 9.05 & \\
\hline & & 1 to 3 & 1.53 & $(-1.7,13.7)$ & $p=0.806$ & & \\
\hline & Model 2: & 1 to (2 and 3 ) & -2.043 & $(-11.9,7.82)$ & $p=0.685$ & 9.03 & 0.6 \\
\hline
\end{tabular}


WOMAC and EQ5D demonstrated equivalence between the reported and confirmed groups. SAPS, WOMAC and EQ5D have been shown to be significantly worse in the reported and confirmed groups compared to those with no AE. Self-reporting an AE may be due to patient perception of an $\mathrm{AE}$ that did not occur. This appears to negatively impact on outcome. The nocebo effect, a negative expectation derived from a clinical encounter, can adversely influence quality of life. Clinician disclosure about potential side effects of medications can itself contribute to reporting AEs, but this effect has not been investigated in the surgical setting [26]. The cyclical nature of negative perceptions around health, mental wellbeing and outcomes are echoed by Perrucio et al. who demonstrated that worse self-reported general health scores predicts less improvement after THR. The patient's perception of health predicts future physical, mental and social outcomes, and this in turn is predicted by the patient's mental well-being [27]. The negative trends seen across WOMAC, EQ5D and patient reported satisfaction, in this study, suggest that patient perception of AEs may influence health outcome.

One aspect that was not investigated as part of this study were the effects of depression on the perception of an AE. Patients with depression have worse pre and postoperative pain and functional scores but experience the same benefit from THR than those without $[28,29]$. The complex interplay of mental well-being, patient perceptions and the impact of AEs with patients' outcomes after THR requires further investigation. Understanding patient perception and identification of AEs may be more thoroughly investigated using qualitative methods designed to gain an in-depth understanding of patients' understanding of $\mathrm{AE}$, experiences, opinions regarding healthcare and the impact of these AEs. An investigation of the impact of depression may further explain the trends we have reported.

The findings in this study are generalisable as the baseline demographics of participants in this study are similar to those reported to in the National Joint Registry for England, Wales and Northern Ireland and the Isle of Man [1]. At 12 months, 23\% of questionnaires sent to patients were not returned, despite sending out reminders. Although a similar non-response level to previous studies, this may affect the internal validity of the study and thus result in some selection bias $[15,30]$. The number of AEs reported and confirmed within this study was relatively small and thus the results of this study should be interpreted with caution. A larger study sample may improve the statistical certainty with which the results can be interpreted.

\section{Conclusion}

In conclusion, patients who report AEs $(8 \%, n=35)$ have worse outcomes than those who do not. Self-reporting of an $\mathrm{AE}$ appears to have a similarly negative impact on outcomes to those with a confirmed AE. Clear information regarding risks and potential $\mathrm{AEs}$, is required, not only for consent, but to ensure patients can correctly identify AEs should they occur. Patients who perceive that they have an $\mathrm{AE}$ may require careful monitoring and support.

\section{Supplementary information}

Supplementary information accompanies this paper at https://doi.org/10. 1186/s12891-020-3127-6.

Additional file 1. Appendix 1: Adverse events questionnaire sent to patients

\section{Abbreviations}

AE: Adverse event; PROM: Patient reported outcome measure; THR: Total hip replacement; WOMAC: Western ontario and mcmaster universities osteoarthritis index; WPAl: Work productivity and activity impairment; EQ5D: EuroQol-5D-3 L; SAPS : Self-administered patient satisfaction

\section{Acknowledgements}

Not applicable.

\section{Ethics approval and to participate}

Using the HRA decision tool, this study does not fall under the remit of research, and our NHS Research and Innovation Department approved the study as a service evaluation project. The HRA guidelines state that consent does not need specifically to be written: Participants provided verbal consent to participate. The questionnaire data that was collected is collected routinely in our practice. As such the only part of this study that was exceptional to routine practice was the patient reporting of adverse events. Ethical approval was not required according to the National Research Ethics Service guidelines. As such, our NHS Research and Innovation Department confirmed that verbal consent was sufficient in this study.

\section{Author's contributions}

CC: Acquisition, analysis and interpretation of the data, drafted the work and prepared the manuscript.

W: Conception and design, interpretation of the data, revision of the drafted work.

AJM: Interpretation of the data, revision of the drafted work.

AS: Analysis and interpretation of the data, revision of the drafted work. AWB: Conception and design, revision of the drafted work.

MRW: Conception and design, acquisition, and interpretation of the data, revision of the drafted work

\section{Authors' information}

Not applicable

\section{Funding}

This study was funded by North Bristol NHS Trust Research Capability Funding scheme and a Medical Research Grant (MR/L01226X/1).

\section{Availability of data and materials}

The datasets used and/or analysed during the current study are available from the corresponding author on reasonable request.

Consent for publication

Participants provided verbal consent to publication of data; no personal information is included in the manuscript.

Competing interests

The authors declare that they have no competing interests. 


\section{Author details}

'Musculoskeletal Research Unit, Translational Health Sciences, Bristol Medical School, 1st Floor Learning \& Research Building, Southmead Hospital, Bristol BS10 5NB, UK. ${ }^{2}$ National Institute for Health Research Bristol Biomedical Research Centre, University Hospitals Bristol NHS Foundation Trust and University of Bristol, Bristol, UK.

Received: 26 July 2019 Accepted: 10 February 2020

Published online: 21 February 2020

\section{References}

1. National Joint Registry for England, Wales and Northern Ireland and the Isle of Man: 15th Annual Report. [http://www.njireports.org.uk/Portals/0/ PDFdownloads/NJR\%2015th\%20Annual\%20Report\%202018.pdf]. Accessed 26 July 2019.

2. Kurtz S, Ong K, Lau E, Mowat F, Halpern M. Projections of primary and revision hip and knee arthroplasty in the United States from 2005 to 2030. J Bone Joint Surg Am. 2007:89(4):780-5.

3. Patel A, Pavlou G, Mújica-Mota R, Toms A. The epidemiology of revision total knee and hip arthroplasty in England and Wales: a comparative analysis with projections for the United States. A study using the National Joint Registry dataset. Bone Joint J. 2015;97(8):1076-81.

4. Arden N, Kiran A, Judge A, Biant L, Javaid M, Murray D, Carr A, Cooper C, Field R. What is a good patient reported outcome after total hip replacement? Osteoarthr Cartil. 2011;19(2):155-62.

5. Abdel M, Houdek M, Watts C, Lewallen D, Berry D. Epidemiology of periprosthetic femoral fractures in 5417 revision total hip arthroplasties. Bone Joint J. 2016;98(4):468-74.

6. Blom AW, Rogers M, Taylor AH, Pattison G, Whitehouse S, Bannister GC. Dislocation following total hip replacement: the Avon Orthopaedic Centre experience. Ann R Coll Surg Engl. 2008;90(8):658-62.

7. Blom AW, Taylor AH, Pattison G, Whitehouse S, Bannister GC. Infection after total hip arthroplasty. Bone Joint J. 2003;85(7):956-9.

8. Enocson A, Pettersson H, Ponzer S, Tornkvist H, Dalen N, Tidermark J. Quality of life after dislocation of hip arthroplasty: a prospective cohort study on 319 patients with femoral neck fractures with a one-year followup. Qual Life Res. 2009:18(9):1177-84.

9. Märdian S, Schaser K-D, Gruner J, Scheel F, Perka C, Schwabe P. Adequate surgical treatment of periprosthetic femoral fractures following hip arthroplasty does not correlate with functional outcome and quality of life. Int Orthop. 2015;39(9):1701-8.

10. Mallon CM, Gooberman-Hill R, Moore AJ. Infection after knee replacement: a qualitative study of impact of periprosthetic knee infection. BMC Musculoskelet Disord. 2018;19(1):352.

11. Moore AJ, Blom AW, Whitehouse MR, Gooberman-Hill R. Deep prosthetic joint infection: a qualitative study of the impact on patients and their experiences of revision surgery. BMJ Open. 2015;5(12):e009495.

12. Cahill JL, Shadbolt B, Scarvell JM, Smith PN. Quality of life after infection in total joint replacement. J Orthop Surg (Hong Kong). 2008;16(1):58-65.

13. Fritz BA, Escallier KE, Abdallah AB, Oberhaus J, Becker J, Geczi K, McKinnon S, Helsten DL, Sharma A, Wildes T. Convergent validity of three methods for measuring postoperative complications. Anesthesiology. 2016;124(6):126576.

14. Alazzawi S, Bardakos N, Hadfield S, Butt U, Beer Z, Field R. Patient-reported complications after elective joint replacement surgery. J Bone Joint Surg Br. 2012;94-B(8):1120-5.

15. Rosner Bl, Gottlieb M, Anderson WN. Accuracy of internet-based patient self-report of Postdischarge health care utilization and complications following orthopedic procedures: observational cohort study. J Med Internet Res. 2018;20(7):e10405.

16. Greenbaum JN, Bornstein LJ, Lyman S, Alexiades MM, Westrich GH. The validity of self-report as a technique for measuring short-term complications after total hip arthroplasty in a joint replacement registry. J Arthroplast. 2012;27(7):1310-5.

17. Reilly MC, Zbrozek AS, Dukes EM. The validity and reproducibility of a work productivity and activity impairment instrument. Pharmacoeconomics. 1993; 4(5):353-65.

18. Bellamy N, Buchanan W, Goldsmith C, Campbell J, Stitt L. Validation study of WOMAC: a health status instrument for measuring clinically important patient relevant outcomes in antirheumatic drug therapy in patients with osteoarthritis of the hip or knee. J Rheumatol. 1988;15(12):1833-40.
19. Group TE. EuroQol - a new facility for the measurement of health-related quality of life. Health Policy. 1990;16(3):199-208.

20. Mahomed N, Gandhi R, Daltroy L, Katz J. The self-administered patient satisfaction scale for primary hip and knee Arthroplasty. Arthritis. 2011; 591253.

21. Phillips CB, Barrett JA, Losina E, Mahomed NN, Lingard EA, Guadagnoli E, Baron JA, Harris WH, Poss R, Katz J. Incidence rates of dislocation, pulmonary embolism, and deep infection during the first six months after elective total hip replacement. JBJS. 2003;85(1):20-6.

22. Bohl DD, Ondeck NT, Basques BA, Levine BR, Grauer JN. What is the timing of general health adverse events that occur after total joint arthroplasty? Clin Orthop Relat Res. 2017:475(12):2952-9.

23. Lamagni T. Epidemiology and burden of prosthetic joint infections. J Antimicrob Chemother. 2014;69(suppl_1):i5-i10.

24. Abdel M, Watts C, Houdek M, Lewallen D, Berry D. Epidemiology of periprosthetic fracture of the femur in 32644 primary total hip arthroplasties: a 40-year experience. Bone Joint J. 2016;98(4):461-7.

25. Meek R, Norwood T, Smith R, Brenkel I, Howie C. The risk of peri-prosthetic fracture after primary and revision total hip and knee replacement. Bone \& Joint Journal. 2011;93(1):96-101.

26. Colloca L, Miller FG. The Nocebo effect and its relevance for clinical practice. Psychosom Med. 2011;73(7):598-603.

27. Perruccio AV, Davis AM, Hogg-Johnson S, Badley E. Importance of self-rated health and mental well-being in predicting health outcomes following total joint replacement surgery for osteoarthritis. Arthritis Care Res (Hoboken). 2011;63(7):973-81

28. Riediger W, Doering S, Krismer M. Depression and somatisation influence the outcome of total hip replacement. Int Orthop. 2010;34(1):13-8.

29. Benditz A, Jansen P, Schaible J, Roll C, Grifka J, Götz J. Psychological factors as risk factors for poor hip function after total hip arthroplasty. Ther Clin Risk Manag. 2017;13:237.

30. Asch DA, Jedrziewski MK, Christakis NA. Response rates to mail surveys published in medical journals. J Clin Epidemiol. 1997;50(10):1129-36.

\section{Publisher's Note}

Springer Nature remains neutral with regard to jurisdictional claims in published maps and institutional affiliations.

Ready to submit your research? Choose BMC and benefit from:

- fast, convenient online submission

- thorough peer review by experienced researchers in your field

- rapid publication on acceptance

- support for research data, including large and complex data types

- gold Open Access which fosters wider collaboration and increased citations

- maximum visibility for your research: over $100 \mathrm{M}$ website views per year

At BMC, research is always in progress.

Learn more biomedcentral.com/submissions 